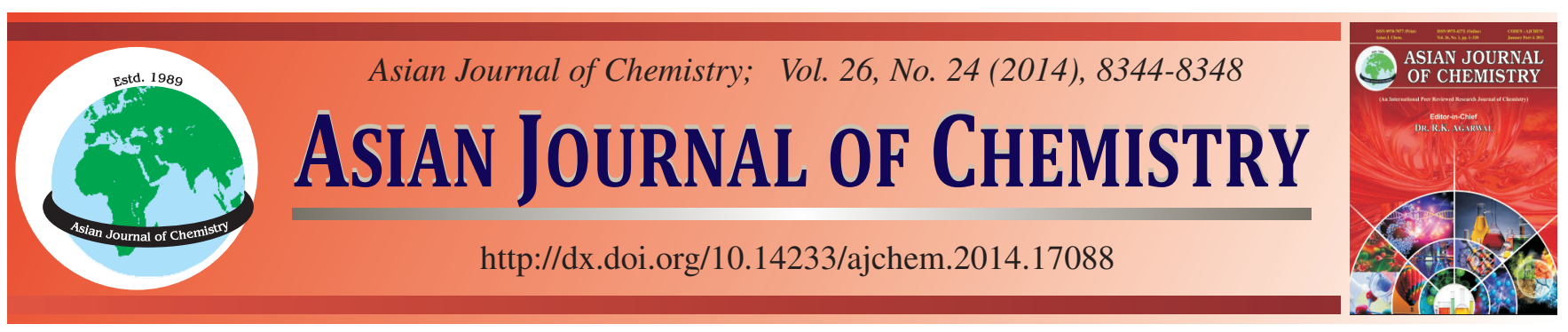

\title{
Design and Controlled-Synthesis of Novel Slightly Crosslinked and Reactive Polycationic Dye-Fixatives for Cotton Fabric
}

\author{
YiKAI Yu ${ }^{1,2, *}$, LiPING DenG ${ }^{3}$ and MeIHUA Yu ${ }^{3}$
}

${ }^{1}$ College of Chemistry and Chemical Engineering, Jiangxi Normal University, Nanchang 330022, P.R. China

${ }^{2}$ Key Laboratory of Chemical Biology of Jiangxi Province, Nanchang 330022, P.R. China

${ }^{3}$ Jiangxi Vocational and Technical College of Information Application, Nanchang 330043, China

*Corresponding author: E-mail: yuyikai1980@163.com

Received: 21 January 2014;

Accepted: 19 April 2014;

Published online: 1 December 2014;

AJC-16357

New series of slightly crosslinked and reactive polycationic dye-fixatives for cotton fabric were synthesized by copolymerization of 3-chloro-2-hydroxypropyltriallyl-ammonium chloride (CHTAAC) and dimethyldiallylammonium chloride. The structures of obtained dye-fixatives could be controlled by varying molar ratios of raw-materials of CHTAAC to DMDAAC during polymerization and their molecular weights were possibly controlled by adjusting different polymerization conditions. The results showed, under the same conditions that the polymerization temperatures were kept at $60^{\circ} \mathrm{C}$ for $6 \mathrm{~h}$ and then heated to $70{ }^{\circ} \mathrm{C}$ for $2 \mathrm{~h}$, when the initial monomer concentrations $(\mathrm{w} / \mathrm{w})$ were increased from 40 to $52.5 \%$ and the initiator amount were gradually decreased from 9 to $5 \%$, a series of slightly crosslinked and reactive polycationic dye-fixatives with 1-5\% molar contents of triallylmethylammonium chloride (TAMAC) units in main chains and controlled intrinsic viscosities of $0.16-0.75 \mathrm{dL} / \mathrm{g}$ were successfully synthesized, which were as designed and could be expected as novel useful dye-fixatives for cotton fabric.

Keywords: Controlled synthesis, 3-Chloro-2-hydroxypropyltriallyl-ammonium chloride, Dimethyldiallylammonium chloride.

\section{INTRODUCTION}

Cotton and other cellulosic fabrics are the most widely used textile in the world, accounting for more than $50 \%$ of total consumption ${ }^{1}$. Dyed cotton must have high colorfastness to repeated domestic launderings at $40-60{ }^{\circ} \mathrm{C}$. By now, poly(dimethyldiallylammonium chloride) (PDMDAAC) has been used as one of the most optimum polycationic dye-fixatives with a view to enhance the uptake of anionic dyes on cotton fabrics and the mechansim of interactions involved can be interpreted by the participation of electrostatic forces between the dyes and the basic cationic groups in the polymer ${ }^{2-6}$. However, it is quite limited for PDMDAAC dye-fixative to improve the rubbing fastness especially wet rubbing fastness of dyes on cotton fabric, due to the possible dissociation of color lakes based on electrostatic forces, which are caused by effect of water molecules, resulting in the dyes' decolorization from cotton fabric ${ }^{7-10}$. This promotes researchers to synthesize new series of promising PDMDAAC-modified dye-fixatives.

Usually, copolymerization of dimethyldiallylammonium chloride (DMDAAC) with one functional monomer is the most popular way to obtain promising PDMDAAC-modified dyefixatives. In our past researches, several reactive PDMDAAC- modified dye-fixatives have been derived from the copolymerization of DMDAAC and one functional monomers with reactive 3-chloro-2-hydroxypropyl groups, which can bring about the covalent reactions with the hydroxyl groups of cotton (cellulose) to form a covering film on cotton surface, resulting in development on the fastness properties of dyes in turn ${ }^{11,12}$. Moreover, those slightly crosslinked PDMDAACs, derived from the copolymerization of DMDAAC and the lower contents (below $5 \%$ molar contents) of crosslinking monomers (triallylmethylammonium chloride), can also exhibit better dye-fixing properties used as polycationic dye-fixatives, possibly due to the plane-like nature of crosslinking structures which would expand the interactions with dyes, resulting in the development of dye-fixing properties too ${ }^{13,14}$. In addition, our research also indicated that the fastness properties of resin dye-fixatives (polymer dye-fixatives) are affected by their molecular weights ${ }^{15}$ and those PDMDAAC dye-fixatives with the controlled molecular weights characterized by intrinsic viscosities of $0.24-0.47 \mathrm{dL} / \mathrm{g}$ have been discovered to exhibit better dye-fixing properties, because their too low intrinsic viscosities would make the interactions with dyes very weak, resulting in the poor dye-fixing properties and too high intrinsic viscosities would make it difficult for them to be penetrated 
into cotton fabrics to interact with dyes, also resulting in the poor dye-fixing properties, thereby their suitable molecular weights should be controlled ${ }^{16-18}$. Therefore, it could be deduced that those cationic polymers of modified PDMDAAC, derived from the further incorporation of lower contents (below $5 \%$ molar contents) of crosslinking units and reactive groups into the backbones of the molecular-weight-controlled PDMDAAC with the controlled intrinsic viscosities of $0.24-0.47 \mathrm{dL} / \mathrm{g}$ or nearly, may be expected as more useful polycationic dyefixatives on cotton fabric, especially, it has not been reported in the open literature. Thus, in view of these points, in this article, the authors expected that new series of slightly crosslinked and reactive polycationic dye-fixatives with controlled intrinsic viscosities and controlled structures could be synthesized by copolymerization of below $5 \%$ molar contents of 3-chloro-2-hydroxypropyltriallylammonium chloride (CHTAAC) (crosslinking monomers with reactive 3-chloro2-hydroxypropyl groups) with dimethyldiallyl ammonium chloride (DMDAAC) (Scheme-I), which were expected as the new candidates for useful polycationic dye-fixatives for cotton fabric. As designed, the structures of obtained dye-fixatives could be controlled by varying molar ratio of raw materials of CHTAAC to DMDAAC from $1 / 99$ to $5 / 95$ during polymerization and their molecular weights represented by the intrinsic viscosities of $0.24-0.47 \mathrm{dL} / \mathrm{g}$ or nearly were possibly controlled by adjusting different polymerization conditions.<smiles>C=CC[N+](C)(C)CC=C</smiles><smiles>C=CC[N+](Cl)(CC=C)CC(O)CCl</smiles>

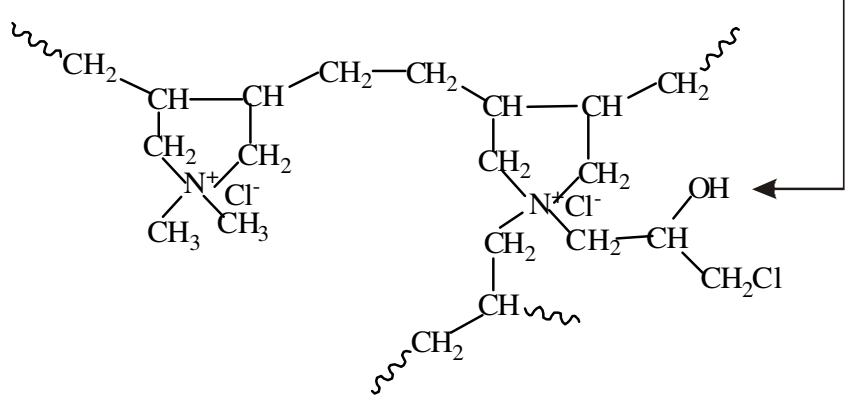

Scheme-I: Design and synthesis of slightly crosslinked and reactive polycationic dye-fixatives

\section{EXPERIMENTAL}

Ammonium persulfate (APS) was purchased from Yixing Tianpeng Fine Chemical Co., Ltd (China). Dimethyldiallyl ammonium chloride was purchased from Luyue Chemical Co., Ltd (China). 3-Chloro-2-hydroxypropyltriallyl-ammonium chloride was synthesized according to our previous contribution ${ }^{19}$.

\section{Controlled-synthesis of slightly crosslinked and reactive} polycationic dye-fixatives: Design and Process

Design for controlled-synthesis of dye-fixatives: A series of slightly crosslinked and reactive polycationic dye-fixatives, which were designed as useful polycationic dye-fixatives for cotton fabric, could be synthesized by copolymerization of CHTAAC and DMDAAC as shown in Scheme-I. As designed, the structures could be controlled by varying molar ratios of raw materials of CHTAAC to DMDAAC during polymerization and their molecular weights represented by the intrinsic viscosities of $0.24-0.47 \mathrm{dL} / \mathrm{g}$ or nearly were possibly controlled by adjusting different polymerization conditions (polymerization temperatures, polymerization time, monomer concentrations and initiator amount) according to theory of the kinetic chain length equation ${ }^{20}$. Therefore, in this article, the effect of different polymerization conditions on the product properties such as intrinsic viscosities and monomer conversions was designed to synthesize a series of slightly crosslinked and reactive polycationic dye-fixatives with controlled structures and controlled intrinsic viscosities.

Controlled-synthesis process of dye-fixatives: As designed earlier, here the synthesis process of one slightly crosslinked and reactive polycationic dye-fixative containing $2 \%$ molar contents of crosslinking units with reactive 3-chloro2-hydroxypropyl groups (CHTAAC units) in main chains was listed as an example as follows: To a $100 \mathrm{~mL}$, round-bottomed flask equipped with a mechanical stirrer, a thermometer, nitrogen inlet and out tubes, calculated amount of dimethyldiallylammonium chloride, triallylmethyl ammonium chloride and deionized water were added, to form a $50 \%(\mathrm{w} / \mathrm{w})$ monomer solution. The polymerization solution was heated to $60{ }^{\circ} \mathrm{C}$ and $5 \%$ amount (w/w, which was equivalent to total monomers amount) of initiator (ammonium persulfate, APS), was added with stirring during a period of 2-3 $\mathrm{h}$ to initiate the polymerization and then the solution was continuously polymerized at $60{ }^{\circ} \mathrm{C}$ for $3-4 \mathrm{~h}$ (the total polymerization time at $60{ }^{\circ} \mathrm{C}$ was controlled to $6 \mathrm{~h}$ ). Finally, the polymerization solution was further heated to $70{ }^{\circ} \mathrm{C}$ for $2 \mathrm{~h}$. One slightly crosslinked and reactive polycationic dye-fixative with $2 \%$ molar contents of CHTAAC units in main chains and the intrinsic viscosity of $0.47 \mathrm{dL} / \mathrm{g}$ could be synthesized. Via the same above-mentioned synthesis process, other slightly crosslinked reactive polycationic dye-fixatives with controlled 1-5\% molar contents of CHTAAC units in main chains and controlled intrinsic viscosities of $0.16-0.75 \mathrm{dL} / \mathrm{g}$ could be synthesized by varying molar ratios of raw materials of CHTAAC to DMDAAC from $1 / 99$ to $5 / 95$ and increasing initial monomer concentrations from 40 to $52.5 \%$ with the decrease of initiator amount from 9 to $5 \%$ during polymerization.

Measurement: The intrinsic viscosities of slightly crosslinked PDMDAACs were used to characterize their molecular weights, which were obtained by measurement of elute time of products solutions in a $1 \mathrm{~mol} / \mathrm{L} \mathrm{NaCl}$ solution at $(30 \pm 1)$ ${ }^{\circ} \mathrm{C}$ according to the literature ${ }^{3}$. The monomer conversions could be approximately accessed by measuring the moles of the residual double bonds in products and were calculated according to the equation, $\mathrm{E}(\%)=\left(1-\frac{\mathrm{x}_{1}}{\mathrm{x}_{0}}\right) \times 100 \%\left(\mathrm{x}_{1}\right.$ was the moles of residual double bonds in copolymers, $\mathrm{x}_{0}$ was the total moles of double bonds in raw monomers) $)^{21}$. The FT-IR spectra of the products in $\mathrm{KBr}$ pellets were recorded using a Nicolet FT-IR (510 P) spectrophotometer. ${ }^{1} \mathrm{H}$ NMR spectra of 
the products were recorded in $\mathrm{D}_{2} \mathrm{O}$ solution on a Bruker DRX$500(500 \mathrm{MHz})$ instrument.

\section{RESULTS AND DISCUSSION}

Controlled synthesis of slightly crosslinked and reactive polycationic dye-fixatives: In order to access the optimum controlled-synthesis method, this study on the effect of different polymerization conditions on properties (intrinsic viscosities and monomer conversions) of one dye-fixative with $2 \%$ molar contents of CHTAAC units in main chains was given as an example and the results were shown in Figs. 1-4.

The results showed that the suitable initial polymerization temperature and initial polymerization time should be, respectively $60{ }^{\circ} \mathrm{C}$ and $6 \mathrm{~h}$. Moreover, the intrinsic viscosities of obtained dye-fixatives were significantly decreased with the increase of initiator amount, which was in agreement with kinetic chain length equation ${ }^{20}$, deducing that the molecular weights of obtained dye-fixatives could be controlled by adjusting the initiator amount during polymerization due to the sensitivity of initiator amount to product intrinsic viscosities. In addition, the intrinsic viscosities of obtained dyefixatives were significantly increased with the increase of the

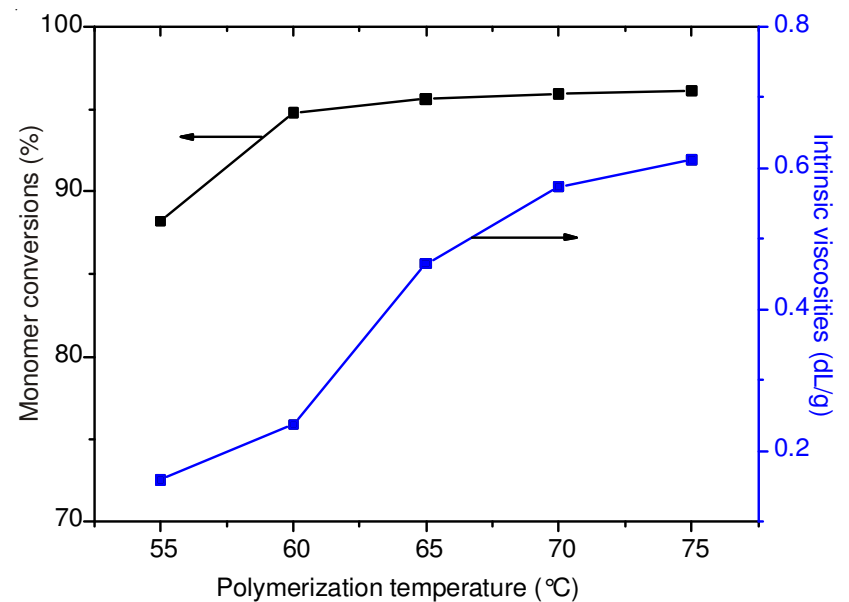

Fig. 1. Effect of polymerization temperatures on properties of dye-fixatives $\mathrm{n}($ CHTAAC $) / \mathrm{n}($ DMDAAC $)=2 / 98$, initial monomer concentration (w/w): $50 \%$, initiator amount $(\mathrm{w} / \mathrm{w}): 5 \%$, polymerization time: $6 \mathrm{~h}$

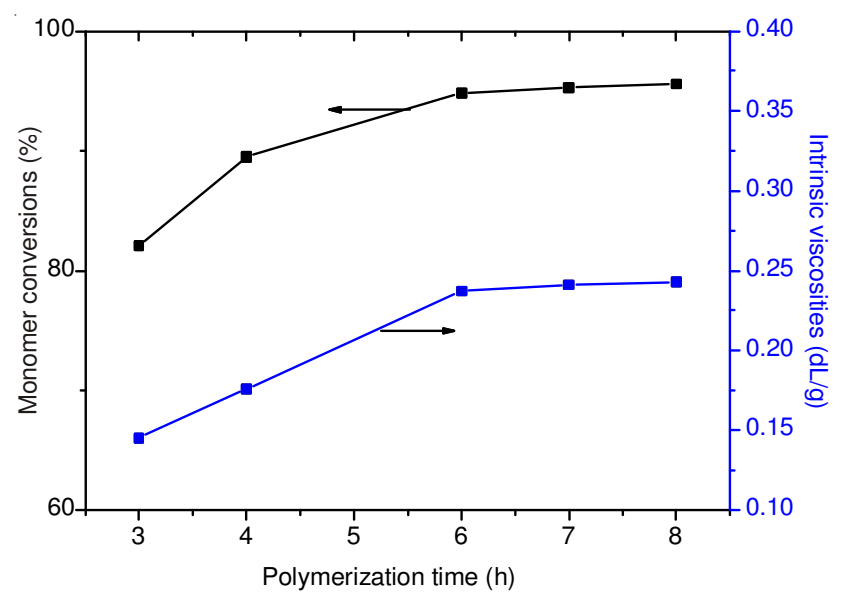

Fig. 2. Effect of polymerization time on properties of dye-fixatives $\mathrm{n}($ CHTAAC $) / \mathrm{n}($ DMDAAC $)=2 / 98$, initial monomer concentration $(\mathrm{w} / \mathrm{w}): 50 \%$, initiator amount $(\mathrm{w} / \mathrm{w}): 5 \%$, initial polymerization temperature: $60{ }^{\circ} \mathrm{C}$

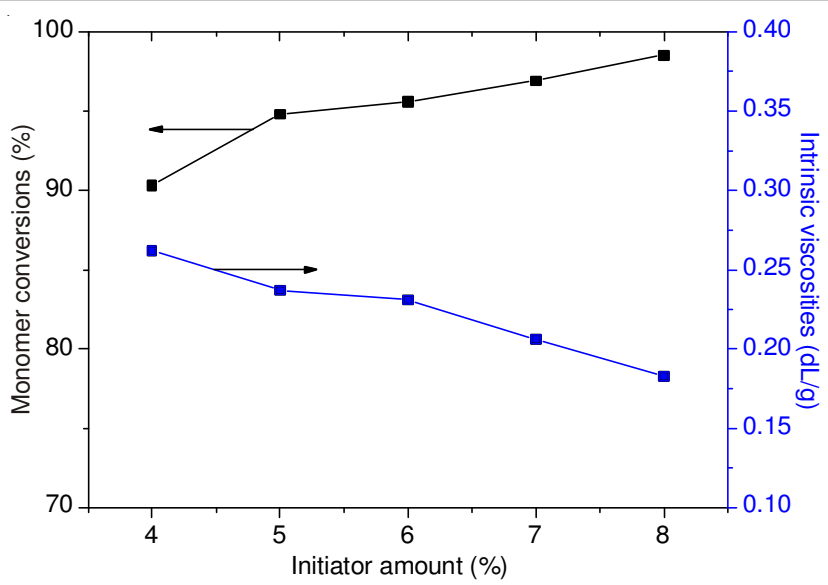

Fig. 3. Effect of initiator amount on properties of dye-fixatives $\mathrm{n}($ CHTAAC $) / \mathrm{n}($ DMDAAC $)=2 / 98$, initial monomer concentration (w/w): $50 \%$, polymerization time: $6 \mathrm{~h}$, initial polymerization temperature: $60^{\circ} \mathrm{C}$

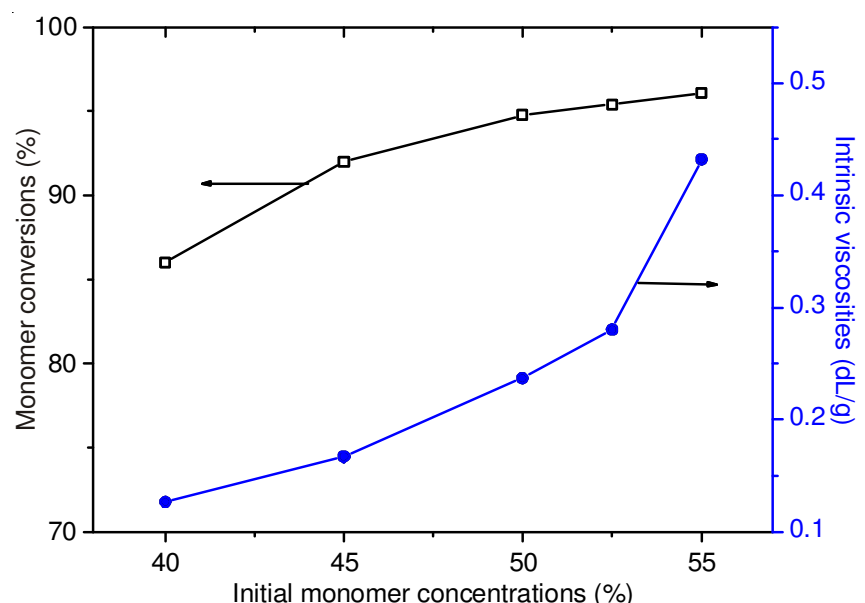

Fig. 4. Effect of initiator monomer concentrations on properties of dyefixatives nCHTAAC) $/ \mathrm{n}(\mathrm{DMDAAC})=2 / 98$, polymerization time: 6 $\mathrm{h}$, initiator amount $(\mathrm{w} / \mathrm{w}): 5 \%$, initial polymerization temperature: $60{ }^{\circ} \mathrm{C}$

initial monomer concentrations during polymerization, which was also in agreement with kinetic chain length equation ${ }^{20}$ and the molecular weights of obtained dye-fixatives could also be controlled by adjusting initial monomer concentrations during polymerization due to the sensitivity of initial monomer concentrations to products' intrinsic viscosities.

With the optimum exploration for synthesis method as established above, a series of slightly crosslinked and reactive polycationic dye-fixatives with controlled structures and controlled intrinsic viscosities of $0.16-0.75 \mathrm{dL} / \mathrm{g}$, which were designed as useful polycationic dye-fixatives for cotton fabric, could be synthesized by varying molar ratios of raw materials of CHTAAC to DMDAAC from $1 / 99$ to $5 / 95$ and increasing initial monomer concentrations from 40 to $52.5 \%$ with the decrease of initiator amount from 9 to $5 \%$ during polymerization, under the same conditions that the polymerization was kept at $60{ }^{\circ} \mathrm{C}$ for $6 \mathrm{~h}$ and then increased to $70{ }^{\circ} \mathrm{C}$ for $2 \mathrm{~h}$ so that the monomer conversions could be stably further increased, which could improve the useful ingredients of products and be beneficial for the development of their dye-fixing properties in turn $^{22}$. The results were given in Table- 1 . 


\begin{tabular}{|c|c|c|c|c|c|}
\hline \multicolumn{6}{|c|}{$\begin{array}{c}\text { TABLE-1 } \\
\text { CONTROLLED-SYNTHESIS OF SLIGHTLY CROSSLINKED } \\
\text { AND REACTIVE POLYCATIONIC DYE-FIXATIVES }\end{array}$} \\
\hline Samples & $\begin{array}{l}\mathrm{n}_{\text {(CHTAAC) }} \\
/ \mathrm{n}_{\text {(DMDAAC) }}\end{array}$ & $\begin{array}{l}\text { Initial monomer } \\
\text { concentration } \\
(w / w \%)\end{array}$ & $\begin{array}{c}\text { Initiator } \\
\text { amount } \\
(\mathrm{w} / \mathrm{w} \%)\end{array}$ & $\begin{array}{c}\text { Intrinsic } \\
\text { viscosity } \\
(\mathrm{dL} / \mathrm{g})\end{array}$ & $\begin{array}{c}\text { Monomer } \\
\text { conversion } \\
(\%)\end{array}$ \\
\hline 1 & $1 / 99$ & 45.0 & 5 & 0.16 & 94.6 \\
\hline 2 & $1 / 99$ & 47.5 & 5 & 0.23 & 95.6 \\
\hline 3 & $1 / 99$ & 50.0 & 5 & 0.27 & 97.0 \\
\hline 4 & $1 / 99$ & 52.5 & 5 & 0.30 & 97.8 \\
\hline 5 & $1 / 99$ & 55.0 & 5 & 0.40 & 98.9 \\
\hline 6 & $1 / 99$ & 57.5 & 5 & 0.54 & 97.1 \\
\hline 7 & $2 / 98$ & 45.0 & 5 & 0.20 & 93.7 \\
\hline 8 & $2 / 98$ & 47.5 & 5 & 0.33 & 94.6 \\
\hline 9 & $2 / 98$ & 50.0 & 5 & 0.47 & 97.2 \\
\hline 10 & $2 / 98$ & 52.5 & 5 & 0.51 & 98.4 \\
\hline 11 & $3 / 97$ & 40.0 & 7 & 0.21 & 95.9 \\
\hline 12 & $3 / 97$ & 45.0 & 5 & 0.31 & 93.3 \\
\hline 13 & $3 / 97$ & 47.5 & 5 & 0.41 & 93.8 \\
\hline 14 & $3 / 97$ & 50.0 & 5 & 0.55 & 94.6 \\
\hline 15 & $3 / 97$ & 52.5 & 5 & 0.75 & 95.2 \\
\hline 18 & $5 / 95$ & 40.0 & 9 & 0.23 & 97.5 \\
\hline 19 & $5 / 95$ & 42.5 & 8 & 0.34 & 96.9 \\
\hline 20 & $5 / 95$ & 45.0 & 7 & 0.42 & 95.1 \\
\hline 21 & $5 / 95$ & 47.5 & 6 & 0.49 & 94.8 \\
\hline 22 & $5 / 95$ & 50 & 6 & 0.73 & 93.7 \\
\hline
\end{tabular}

Moreover, the bending absorptions of the $=\mathrm{CH}$ linkage at $884 \mathrm{~cm}^{-1}$ (due to the DMDAAC monomer) and $880 \mathrm{~cm}^{-1}$ (due to the CHTAAC monomer) were both absent, indicating that the expected copolymerization of CHTAAC monomer with DMDAAC monomer occurred. Thus, it could be indicated that the structures of slightly crosslinked and reactive polycationic dye-fixatives were as expected.

${ }^{1}$ H NMR analysis of dye-fixatives: The ${ }^{1} \mathrm{H}$ NMR analysis of obtained PDMDAAC, one product and CHTAAC monomer were shown in Figs. 6-8.

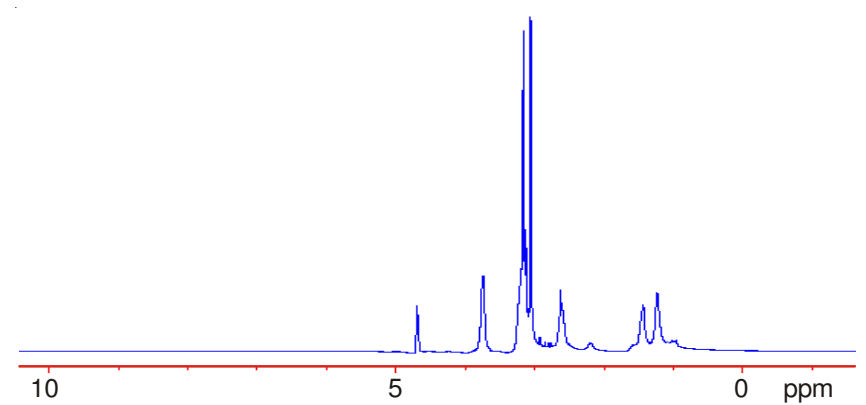

Fig. 6. ${ }^{1} \mathrm{H}$ NMR analysis of PDMDAAC

FT-IR analysis of dye-fixatives: The FT-IR analysis of obtained products was shown in Fig. 5. Fig. 5 showed, the FT-IR spectra (peak 1) of all the slightly crosslinked PDMDAACs were similar to that of PDMDAAC and all the FT-IR spectra had the stretching absorption of the $-\mathrm{CH}_{3}$ groups at $3014 \mathrm{~cm}^{-1}$, the stretching absorption of the $-\mathrm{CH}_{2}$ - linkage at $2937 \mathrm{~cm}^{-1}$, the stretching absorption of the methyne linkage at $2868 \mathrm{~cm}^{-1}$, which were similar to that of PDMDAAC and could be attributed to the DMDAAC units, indicating that the structures of slightly crosslinked PDMDAACs were based on PDMDAAC.

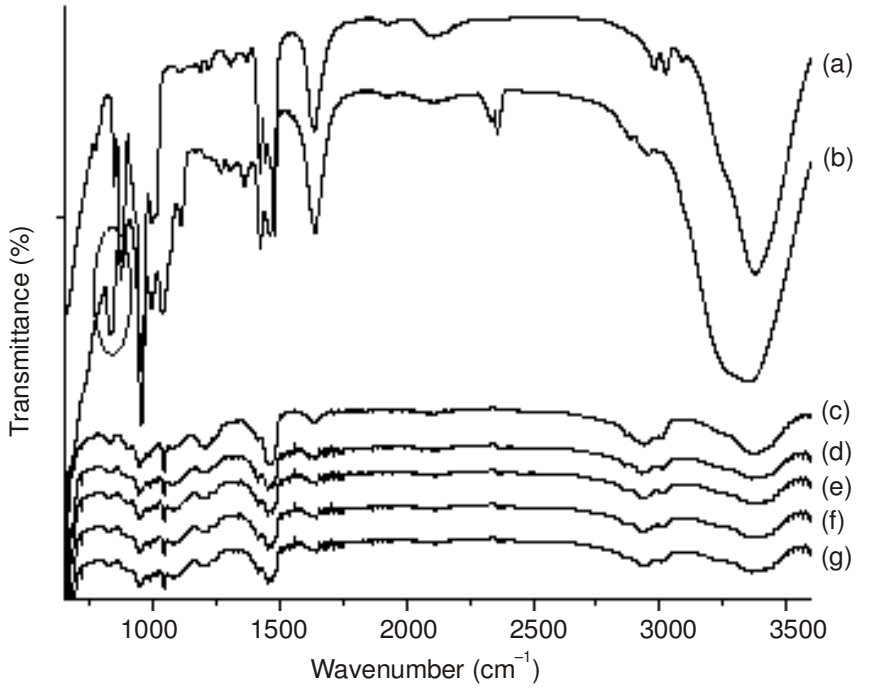

Fig. 5. FT-IR analysis of slightly crosslinked and reactive polycationic dyefixatives (a) DMDAAC (monomer); (b) CHTAAC (monomer); (c) PDMDAAC (0\% molar contents of TAMAC); (d) $1 \%$ molar contents of TAMAC (no. 1); (e) $2 \%$ molar contents of TAMAC (no. 5); (f) $3 \%$ molar contents of TAMAC (No. 10); (g) $5 \%$ molar contents of TAMAC (no. 14)

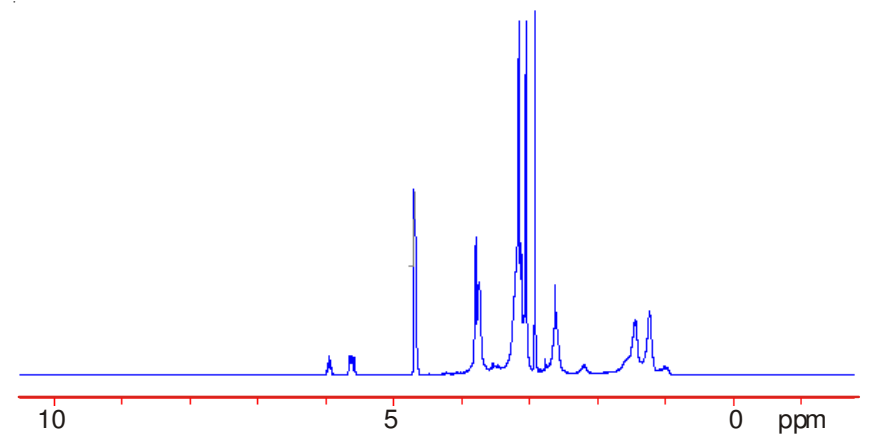

Fig. 7. ${ }^{1} \mathrm{H}$ NMR analysis of one dye-fixative (no. 14)

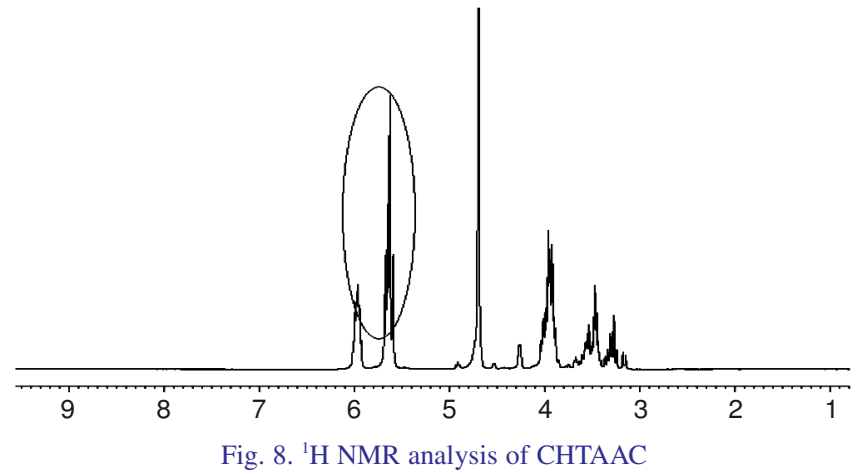

It was showed in Fig. 6, the ${ }^{1} \mathrm{H}$ NMR spectra of the PDMDAAC had the characteristic peak of a $\mathrm{N}^{+}-\mathrm{CH}_{2}$ - linkage in DMDAAC unit at $3.75 \mathrm{ppm}, \mathrm{a}-\mathrm{CH}_{3}$ group at 3.06-3.15 ppm, a methyne unit at $2.63 \mathrm{ppm}$ and the $-\mathrm{CH}_{2}$ - linkage at 1.25 $1.43 \mathrm{ppm}$.

Fig. 7 showed, the ${ }^{1} \mathrm{H}$ NMR spectra of one slightly crosslinked PDMDAAC (no. 21) had the characteristic peak of a $\mathrm{N}^{+}-\mathrm{CH}_{2}$ - linkage at $3.79 \mathrm{ppm}$, the characteristic peak of a $-\mathrm{CH}_{3}$ group at 3.05-3.18 ppm, the characteristic peak of a methyne unit at $2.63 \mathrm{ppm}$ and the characteristic peak of $-\mathrm{CH}_{2}-$ 
linkages in the polymers' main chains at $1.24-1.45 \mathrm{ppm}$, which were similar to those of PDMDAAC and could be attributed to the DMDAAC units.

Moreover, compared to the ${ }^{1} \mathrm{H}$ NMR spectra of the CHTAAC monomer (Fig. 8), the characteristic peak of a $\mathrm{CH}_{2}=\mathrm{CH}-$ linkage at 5.60-6.01 ppm was absent, further indicating that the expected copolymerization of TAMAC monomer with DMDAAC monomer occurred. Thus, the ${ }^{1} \mathrm{H}$ NMR spectra further indicated that that the structures of slightly crosslinked and reactive dye-fixatives were as expected.

\section{Conclusion}

A series of novel slightly crosslinked and reactive polycationic dye-fixatives with controlled-structures and controlled intrinsic viscosities of $0.16-0.75 \mathrm{dL} / \mathrm{g}$, by varying molar ratios of raw materials of CHTAAC to DMDAAC from 1/99 to 5/95 and increasing initial monomer concentrations from 40 to $52.5 \%$ with the decrease of initiator amount from 9 to $5 \%$ during polymerization. FT-IR analysis and ${ }^{1} \mathrm{H}$ NMR analysis confirmed their structures, which were as designed and could be expected as novel useful reactive polycationic dye-fixatives for cotton fabric.

\section{ACKNOWLEDGEMENTS}

This work has been supported by Science and Technology Project of Education Department of Jiangxi Province (No. GJJ13213).

\section{REFERENCES}

1. H.F. Wang, Y.Y. Cheng and H. Lin, J. Soochow Univ., 23, 12 (2003).

2. H. Kishioka, JP 56128382 (1981).

3. C. Wandrey, J. Hernández-Barajas and D. Hunkeler, Adv. Polym. Sci., 145, 123 (1999).

4. X. Jia and Y.J. Zhang, Fine Chemicals, 25, 1008 (2008).

5. Y.M. Deng, J. Dongguan Univ. Technol., 17, 51 (2010).

6. R.S. Blackburn and S.M. Burkinshaw, J. Appl. Polym. Sci., 89, 1026 (2003).

7. S.M. Burkinshaw and A. Gotsopoulos, Dyes Pigments, 42, 179 (1999).

8. S.M. Burkinshaw and A. Gotsopoulos, Dyes Pigments, 32, 209 (1996).

9. S.M. Burkinshaw and D. Katsarelias, Dyes Pigments, 29, 139 (1995).

10. X. Zhang, B. Mao and M.H. Xiang, Textile Auxiliaries, 22, 5 (2005).

11. Y.K. Yu and Y.J. Zhang, Res. Chem. Intermed., 38, 2097 (2012).

12. Y.K. Yu and Y.J. Zhang, J. Chemistry, Article ID 365103 (2013).

13. Y.K. Yu and Y.J. Zhang, J. Chinese Chem. Soc., 58, 428 (2011).

14. Y.K. Yu and Y.J. Zhang, Macedonian J. Chem. Chem. Eng., 32, 125 (2013).

15. Y.K. Yu and Y.J. Zhang, J. Textile Res., 31, 145 (2010).

16. W.C. Qu, Study on Synthesis of Poly(Diallyldimethylammonium Chloride) - The Systematic Researches on the Processes of Preparing DyeFixative and Preliminary Researches on the Processes of Preparing Water Treatment, Nanjing University of Science and Technology, Nanjing (1998).

17. Y.K. Yu and Y.J. Zhang, J. Vinyl Additive Technol., 16, 277 (2010).

18. K. Komiya, S. Kanai and K. Beppu, JP Patent 63,264,985 (1988).

19. Y.K. Yu and Y.J. Zhang, Fine Chemicals, 28, 400 (2011).

20. Z.R. Pan, Polymer Chemistry, Beijing Chemical Industry Press, Beijing, edn 3, pp. 43-44 (2003).

21. X. Jia and Y.J. Zhang, Chinese J. Appl. Chem., 24, 610 (2007).

22. X. Jia, Y.J. Zhang and P.Z. Yu, Petrochemical Technol., 37, 49 (2008). 